\title{
First-line therapies for Helicobacter pylori eradication: a critical reappraisal of updated guidelines
}

\author{
Vincenzo De Francesco ${ }^{a}$, Annamaria Bellesiaa, Lorenzo Ridolab, Raffaele Mantac, Angelo Zullod \\ Riuniti Hospitals, Foggia; Sapienza University of Rome, Polo Pontino, Latina; Nuovo Ospedale Civile \\ Sant'Agostino-Estense, Baggiovara-Modena; Nuovo Regina Margherita Hospital, Rome, Italy
}

\begin{abstract}
Helicobacter pylori (H. pylori) treatment remains a challenge for the clinician, as no available therapy is able to cure the infection in all treated patients. In the last two decades, several antibiotic combinations have been proposed, including triple therapies, bismuth-free therapies (sequential, concomitant, hybrid regimens), and bismuth-based quadruple therapy. Some national and international guidelines on $\mathrm{H}$. pylori management have recently been updated, recommending or discouraging the use of each of these therapeutic approaches, based mainly on the presumed pattern of primary antibiotic resistance in different geographic areas. We examined the recommendations on first-line therapies in the most recently updated guidelines worldwide, taking into account other data affecting the efficacy of a therapy regimen beyond the primary resistance pattern. Although several guidelines highlighted that the results achieved by an eradication therapy are populationspecific and not directly transferable, it emerged that some therapy regimens are recommended or discouraged with no mention of the vital need for national data.
\end{abstract}

Keywords Helicobacter pylori, therapy, sequential, concomitant, hybrid, bismuth salts, guidelines, bacterial resistance

Ann Gastroenterol 2017; 30 (4): 1-7

\section{Introduction}

Choosing a treatment for Helicobacter pylori (H. pylori) eradication in a definite geographic area relies on different factors, such as the local availability of antimicrobial agents, the pattern of primary antibiotic resistance, and the therapeutic cost [1]. In a specific patient, the probability of successful therapy is affected by several host and bacterial factors [2], but patient compliance and bacterial resistance to antibiotics play a major role. Compliance with an eradication therapy, in turn, depends on regimen complexity, tolerability, and the incidence of related

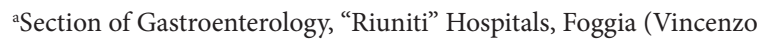
De Francesco, Annamaria Bellesia); ${ }^{\mathrm{b}}$ Gastroenterology Unit, "Sapienza" University of Rome, Polo Pontino, Latina (Lorenzo Ridola); 'Gastroenterology Unit, Nuovo Ospedale Civile Sant'Agostino-Estense, Baggiovara-Modena (Raffaele Manta); ${ }^{\mathrm{d}}$ Gastroenterology and Digestive Endoscopy, "Nuovo Regina Margherita" Hospital, Rome (Angelo Zullo), Italy

Conflict of Interest: None

Correspondence to: Dr. Vincenzo De Francesco, AOU

Gastroenterologia, Ospedali Riuniti di Foggia, Viale Pinto, 71100

Foggia, Italy, Tel.: +39 0881 733776, Fax: +39 0881 736218,

e-mail: vdefrancesco@alice.it

Received 24 April 2017; accepted 18 May 2017; published online 1 June 2017

DOI: https://doi.org/10.20524/aog.2017.0166 side-effects. Good compliance, defined as a concordance of more than $90 \%$ between the prescribed and the ingested drugs, significantly increases the eradication rate [3]. The presence of $H$. pylori strains resistant towards a certain antibiotic is associated with its consumption in the general population, or its previous use in the same patient to treat other infections [4,5]. A high prevalence of resistance to primary clarithromycin $(>15 \%)$ or metronidazole (>30\%) in $\mathrm{H}$. pylori isolates reduces the efficacy of standard first-line therapies that include these drugs [6,7]. This suggests that efforts in assessing local, regional, and national patterns of antimicrobial resistance should be performed to allow an appropriate selection of $H$. pylori therapies $[8,9]$. However, following standard therapies, bacterial eradication may be achieved in a definite number (up to 38.5\%) of patients despite the presence of clarithromycin and/or metronidazole resistance [10]. Indeed, the combination of different synergic antibiotics may allow the resistance towards a specific molecule to be overcome. On the other hand, the infection is not cured in a distinct portion (19.6\%) of patients even when susceptible H. pylori strains are present [10], as several other factors apart from the bacterial susceptibility status are involved [2]. These findings suggest a significant discordance between the expected eradication rate based on antimicrobial resistance assessment in vitro and the actual performance in vivo for each therapy regimen. Therefore, monitoring the efficacy of standard therapies in a particular area, irrespective of the prevalence of antibiotic resistance, is of paramount relevance before a still potentially successful therapy is abandoned [11]. 
Since the 1990s, different national and international guidelines for the management of patients with $H$. pylori infection have been introduced and periodically updated. Undeniably, recommendations on some issues are universally applicable to different geographic areas, such as those concerning the indications for treatment, or diagnostic procedures. For instance, H. pylori infection should be searched for in all patients with a peptic ulcer, irrespectively of the country where they are living. Likewise, the accuracy of noninvasive or invasive tests does not change among patients of different geographic areas. Therefore, guidelines on diagnosis and clinical issues may be applicable in all countries. In contrast, the efficacy of a therapy regimen may be affected by local or regional host/ bacterial peculiarities $[8,9]$. Consequently, recommendations on therapeutic approaches are more appropriately addressed in national rather than international guidelines, provided that data from national studies are considered.

Based on all these considerations, we aimed to examine the most recently updated guidelines worldwide, focusing our attention on first-line therapy recommendations for $H$. pylori eradication. Specifically, we considered European [8], NICE [12], Italian [13], Spanish [14] American [9] and Canadian [15] guidelines for Western countries, and Asian [16], Australian [17], Japanese [18], and Chinese [19] guidelines for Eastern countries.

\section{Clarithromycin-based triple therapies}

In the last two decades, $H$. pylori treatment has been largely focused on triple therapies based on clarithromycin, which is the most powerful antibiotic against $H$. pylori strains [20]. To date, there is well documented evidence regarding the decreasing efficacy of these regimens as a result of the increased prevalence of primary resistance to clarithromycin and metronidazole. Following standard 7-day triple therapies, an eradication rate less than $80 \%$ has repeatedly been reported in several countries [21], so that a 14-day regimen has been proposed to improve the success rate. A recent Cochrane systematic review [22] and a large network meta-analysis [23] found that the prolonged 14day regimen achieves a higher eradication rate compared to the 7- and 10-day schedules, although the therapeutic gain was only $+8 \%$. However, a 7 -day triple therapy is still recommended in all Eastern guidelines apart from the Chinese, mainly depending on a particular prescriptive policy for antimicrobial drugs (Table 1). Conversely, among western guidelines, only one suggests the use of a 7-day triple therapy [12], whilst European, American and Canadian, but not Spanish, guidelines conditionally recommend a 14-day regimen, limiting its use in those geographic areas to low $(<15 \%)$ clarithromycin resistance and for patients not previously exposed to macrolides (Table 2). Surprisingly, the use of a 14day triple therapy is still suggested in the Italian guidelines, even though the primary clarithromycin resistance rate is definitely $>15 \%$ in Italy [5,7]. Moreover, there are only 3 studies on 14day triple therapy performed in Italy, which concordantly found that the success rate was lower than $75 \%$ and $80 \%$ in intentionto-treat (ITT) and per-protocol analyses, respectively (Table 3) [24-26]. Unfortunately, the eradication rate of 14-day triple therapy was not significantly increased even by using a doubledose proton-pump inhibitor (PPI) (i.e. esomeprazole $40 \mathrm{mg}$ b.i.d.) [26]. Therefore, the recommendation for using a 14-day triple therapy in the updated Italian guidelines would appear at least questionable. For instance, based on the disappointing results of national studies [27], the Spanish guidelines wisely excluded 14-day triple therapies from the recommended treatments [14]. In contrast, in Latin America [28], the cure rate following the 14-day clarithromycin-amoxicillin triple therapy $(82.2 \%)$ was higher than that of either concomitant $(73.6 \%)$ or sequential $(76.5 \%)$ therapies, most probably because of the very high $(>80 \%)$ prevalence of metronidazole resistance in the $H$. pylori strains. Therefore, the same therapy regimen may be more successful in a specific geographic area than in another.

\section{Bismuth-free therapies}

In order to overcome the decreasing efficacy of triple therapies, alternative regimens combining the few available antibiotics active against $H$. pylori strains have been pioneered during the last 15 years [29]. These include the sequential, concomitant and hybrid therapy regimens, schematically described in Table 4 . In the current guidelines, the use of these treatments is recommended or not, based on different discriminating factors, such as regimen complexity, the impact of isolate or combined antimicrobial primary resistance, and the geographic variations in their efficacy. Each of these aspects could be susceptible to reappraisal.

The complexity of sequential therapy has been emphasized in different guidelines, and it relies on the need to change antibiotics during treatment, which, in turn, could result in low patient compliance. The same limitation has also been ascribed to the hybrid therapy regimen, the use of which is not recommended by any current guidelines, with only the US and Spanish guidelines advocating that further data are needed. Therefore, some opinion leaders criticized the concept of "sequential" administration of antibiotics, suggesting that a "concomitant" use of 3 antibiotics would favor patient compliance and increase therapeutic efficacy [30]. Nevertheless, we were unable to find any published data in the literature supporting a difference in compliance rate between sequential and concomitant therapies. On the contrary, the time needed for explaining the therapeutic regimen to the patients was specifically addressed in a large study, which found a similarly short $(<5 \mathrm{~min})$ time among sequential, concomitant and hybrid regimens, with no difference between patients with a high or low educational level [31]. In addition, a recent review network meta-analysis found that tolerability and compliance with sequential therapy were similar when compared to triple therapy, as well as to a concomitant therapy regimen, which is associated with even more side-effects [23]. After all, it is improbable that a 10-day therapy with a total of 50 tablets (sequential regimen) is associated with a lower compliance than that of a 14-day therapy with 112 tablets (concomitant regimen). Therefore, the emphasis on regimen complexity, which features in current guidelines as a discriminating factor for choosing a treatment, seems not to be supported by objective data. 
Table 1 First-line therapies recommended in Eastern guidelines

\begin{tabular}{lllll}
\hline Therapy & Asia 2009 [16] & Japan 2010 [18] & China 2013 [19] & Australia 2014 [17] \\
\hline Triple & Recommended 7 days & Recommended 7 days & Not recommended & Recommended 7 days \\
Sequential & Not recommended & Suspended judgment ${ }^{1}$ & No recommended & Suspended judgment $^{1}$ \\
Concomitant & Not contemplated & Suspended judgment ${ }^{1}$ & Suspended judgment $^{1}$ & Not contemplated $^{\text {Nybrid }}$ \\
Bismuth-based & Not contemplated & Not contemplated & Not contemplated & Not contemplated \\
\hline
\end{tabular}

${ }^{1}$ Lacking studies or evidences; [Ref]

$\underline{\text { Table } 2 \text { First-line therapy recommended in Western guidelines }}$

\begin{tabular}{|c|c|c|c|c|c|c|}
\hline Therapy & $\begin{array}{l}\text { NICE } \\
2014 \text { [12] }\end{array}$ & $\begin{array}{l}\text { Italy } \\
2015 \text { [13] }\end{array}$ & $\begin{array}{l}\text { Spain } \\
2016[14]\end{array}$ & $\begin{array}{l}\text { Europe } \\
2016[8]\end{array}$ & $\begin{array}{l}\text { Canada } \\
2016[15]\end{array}$ & $\begin{array}{l}\text { USA } \\
2017 \text { [9] }\end{array}$ \\
\hline Triple & $\begin{array}{l}\text { Recommended } \\
7 \text { days }\end{array}$ & $\begin{array}{l}\text { Recommended } \\
14 \text { days }\end{array}$ & $\begin{array}{l}\text { Not } \\
\text { recommended }\end{array}$ & $\begin{array}{l}\text { Conditionally } \\
\text { recommended } \\
14 \text { days }^{1}\end{array}$ & $\begin{array}{l}\text { Conditionally } \\
\text { recommended } \\
14 \text { days }^{1}\end{array}$ & $\begin{array}{l}\text { Conditionally } \\
\text { recommended } \\
14 \text { days }^{1}\end{array}$ \\
\hline Sequential & $\begin{array}{l}\text { Not } \\
\text { contemplated }\end{array}$ & Recommended & $\begin{array}{l}\text { Not } \\
\text { recommended }\end{array}$ & $\begin{array}{l}\text { Not } \\
\text { recommended }\end{array}$ & $\begin{array}{l}\text { Not } \\
\text { recommended }\end{array}$ & $\begin{array}{l}\text { Conditionally } \\
\text { recommended }^{2}\end{array}$ \\
\hline Concomitant & $\begin{array}{l}\text { No } \\
\text { contemplated }\end{array}$ & Recommended & $\begin{array}{l}\text { Recommended } \\
14 \text { days }\end{array}$ & $\begin{array}{l}\text { Recommended } \\
14 \text { days }\end{array}$ & $\begin{array}{l}\text { Recommended } \\
14 \text { days }\end{array}$ & $\begin{array}{l}\text { Recommended } \\
10-14 \text { days }\end{array}$ \\
\hline Hybrid & $\begin{array}{l}\text { Not } \\
\text { contemplated }\end{array}$ & $\begin{array}{l}\text { Not } \\
\text { contemplated }\end{array}$ & $\begin{array}{l}\text { Suspended } \\
\text { judgment }^{2}\end{array}$ & $\begin{array}{l}\text { Not } \\
\text { contemplated }\end{array}$ & $\begin{array}{l}\text { Not } \\
\text { contemplated }\end{array}$ & $\begin{array}{l}\text { Suspended } \\
\text { judgment }^{2}\end{array}$ \\
\hline Bismuth-based & $\begin{array}{l}\text { Recommended } \\
7 \text { days }\end{array}$ & $\begin{array}{l}\text { Suspended } \\
\text { judgment }{ }^{2}\end{array}$ & $\begin{array}{l}\text { Recommended } \\
14 \text { days }\end{array}$ & $\begin{array}{l}\text { Recommended } \\
10 \text { or } 14 \text { days }\end{array}$ & $\begin{array}{l}\text { Recommended } \\
14 \text { days }\end{array}$ & $\begin{array}{l}\text { Recommended } \\
14 \text { days }\end{array}$ \\
\hline
\end{tabular}

${ }^{1}$ Only in those area with a low $(<15 \%)$ prevalence of primary clarithromycin resistance. ${ }^{2}$ Lacking studies or evidence; [Ref]

Table 3 Eradication rate following 14-day triple therapies in Italy

\begin{tabular}{lllcc}
\hline Study & Year & Disease & ITT eradication rate (\%) & PP eradication rate (\%) \\
\hline Paoluzi et al. [24] & 2006 & NUD/PUD & $156 / 247(63.1)$ & $156 / 209(74.6)$ \\
Zagari et al [25 ] & 2007 & PUD & $246 / 301(81.7)$ & $185 / 218(84.9)$ \\
De Francesco et al [26] & 2016 & NUD/PUD & $54 / 73(74)$ & $54 / 69(78.3)$ \\
Total & & & $456 / 621(73.4)$ & $395 / 496(79.6)$ \\
\hline
\end{tabular}

ITT, intention to treat; PP, per protocol; NUD, non-ulcer dyspepsia; PUD, peptic ulcer disease

The pattern of primary bacterial resistance towards different antibiotics may be a cause for concern. Indeed, different guidelines suggest choosing the first-line therapy according to regional or national prevalence of antimicrobial resistance in $H$. pylori isolates $[8,9,15]$. Specifically, a prevalence rate $>15 \%$ for combined resistance towards clarithromycin and metronidazole is recognized as the major factor impairing efficacy of all bismuth-free therapies [6], whilst an isolate resistance rate $>20 \%$ to clarithromycin undermines the efficacy of triple and sequential therapies, but not the concomitant regimen [8]. Nevertheless, at least three meta-analyses, including data from studies performed in areas with different prevalences of antibiotic resistance, have shown a similar efficacy between sequential and concomitant therapies [32-34]. Therefore, $a$ priori discrimination with respect to a particular therapy based only on the presumed prevalence of bacterial resistance in a geographic area seems to be at least questionable, and local validation of each therapy regimen would be desirable. Indeed, factors beyond the antibiotic resistance pattern could play a role, causing different results in diverse geographic areas. For instance, primary resistance towards either clarithromycin or metronidazole in $H$. pylori isolates is as high as $30 \%$ in Italy $[5,7]$, so that the sequential therapy should not be used according to the European guidelines [8]. However, in the last decade, an eradication rate of $>90 \%$ has repeatedly been found in all multicenter Italian trials involving thousands of patients [35,36], apart from one study published in 2010 where the infection was cured in $83 \%$ of 122 patients [37]. When considering only data from studies published in the last 5 years, the cure rate following sequential therapy was still $90-92.6 \%$ in 5 Italian studies with more than 1000 patients [26,38-41], and 73\% in another study with 100 cases [42]. A similarly high success rate of sequential therapy has been observed in studies recently performed in Slovenia (94.2\%) [43], Portugal (90\%) [44], Belgium (90\%) [3], Israel (95.9\%) [45], Thailand (94\%) [46], Taiwan (91.9\%) [47], Singapore (90.3\%) [48], and the United 
Table 4 Therapy regimens suggested for Helicobacter pylori eradication in the current guidelines

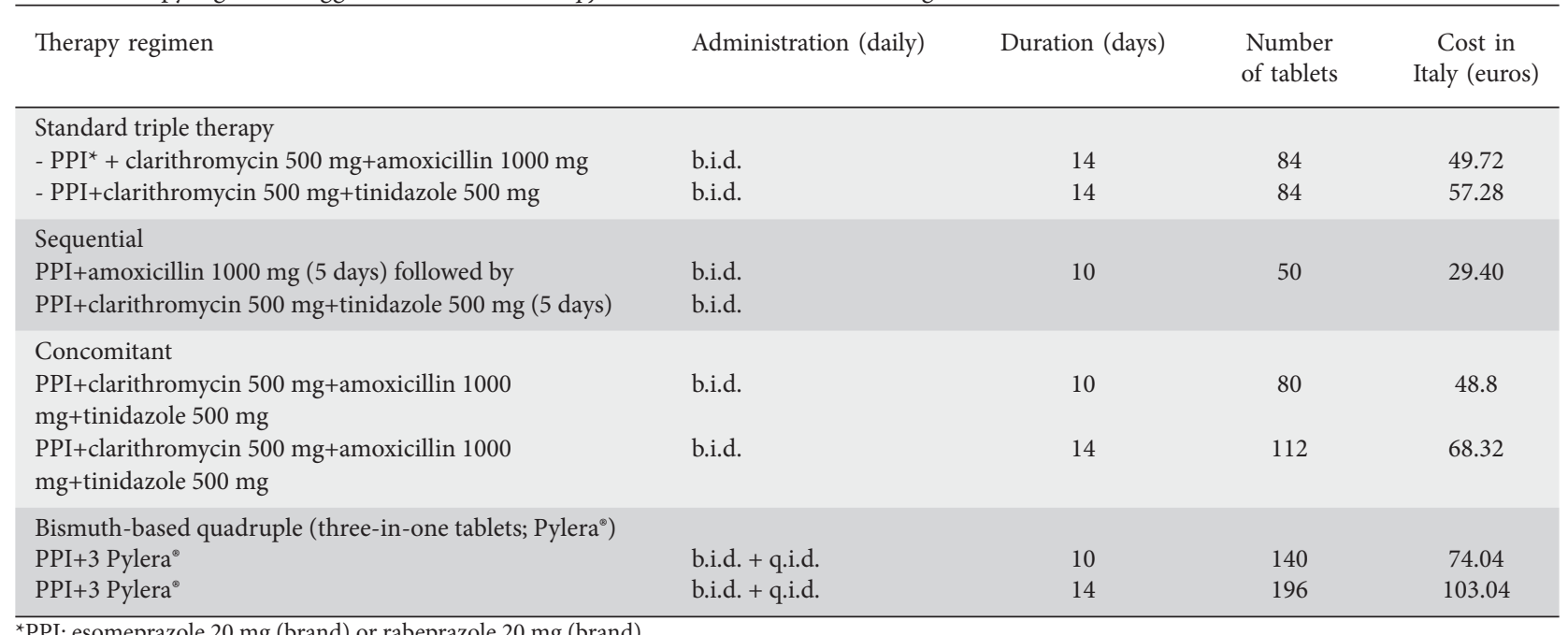

${ }^{*}$ PPI: esomeprazole $20 \mathrm{mg}$ (brand) or rabeprazole $20 \mathrm{mg}$ (brand)

Arab Emirates (88.6\%) [49], suggesting that this therapy is still effective in several countries. Based on these findings, Italian, Slovenian, or Portuguese physicians could inopportunely deprive their patients a priori of a still effective therapy by following the European guidelines. In contrast, unsatisfactory cure rates were observed in Greece [50], Spain [51], Ireland [52], Turkey [53], Iran [54], Korea [55], China [56], and Puerto Rico [57]. Notably, the difference among results achieved by sequential therapy in different geographic areas could be due, at least in part, to the type of nitroimidazole used. In several studies, metronidazole $400 \mathrm{mg}$ b.i.d. has been administered instead of tinidazole $500 \mathrm{mg}$ b.i.d., and it has been found that the tinidazole-based regimen achieved significantly higher cure rates than metronidazole-based sequential therapy [36]. Indeed, apart from the higher dose, tinidazole possesses a markedly higher half-life compared to metronidazole [36].

Considering the geographic variations in cure rate achieved by an eradication regimen it was astonishing to note that some national guidelines discourage the use of a certain therapy, despite a lack of robust data coming from the same geographic area. For instance, the Canadian guidelines recommend against sequential therapy, although only one study was performed in that country [58]. Specifically, a total of 104 patients from Arctic aboriginal community were enrolled, with 51 cases in the sequential therapy and 49 in the triple therapy arm, showing disappointing results for both therapies. Irrespective of the efficacy, can the results of a single, small study of Canada's Arctic population be extended to the entire Canadian population? Notably, it has been demonstrated that compliance with either triple or sequential therapies in the studied population was perfect in only $64 \%$ and good in another $16 \%$ of patients [59]. Can a therapy regimen efficacy be reliably assessed when tablets are taken correctly by only half of the patients? Are we sure that the result observed in the Arctic circle population is the same achievable in Toronto or Vancouver? It could be suggested that greater caution should be adopted in the preparation of statements for guidelines when national data are limited or even lacking. Indeed, a guideline statement influences the decisions of thousands of physicians, with potential consequences for millions of patients. For instance, US and Japanese guidelines correctly suggest that no reliable evaluation of sequential therapy is possible, since there is a lack of specific data for their countries $[9,18]$.

\section{Bismuth-based quadruple therapies}

Undeniably, 14-day triple therapy with bismuth salts, tetracycline and metronidazole was the first therapy to achieve consistently high $H$. pylori eradication rates. This therapy was introduced and largely used in the second part of the 1980s. The decline of such a regimen was mainly due to its intrinsic complexity (large number of tablets, q.i.d. administration, frequent side-effects) and to the rise of simpler and more tolerable triple therapies. In order to improve compliance with the bismuth-based triple therapy, a PPI has been added, aiming to reduce side-effects and shortening therapy length to only 4-7 days, thus configuring the bismuth-based quadruple therapy $[60,61]$. Unfortunately, some delivery problems have arisen with bismuth salts in Europe and tetracycline in the US, so that the use of quadruple therapy in several countries has been greatly limited in the last decade. The interest in such a regimen has recently been renewed by the marketing of a novel, three-in-one capsule (Pylera ${ }^{\circledR}$ ) that was first proposed in 2001, each pill containing bismuth subcitrate potassium (140 mg), metronidazole (125 mg) and tetracycline (125 mg) [62]. The bismuth-based quadruple therapy is included among the recommended first-line therapies in the current European, US, Canadian and Chinese guidelines $[8,9,15,19]$. Surprisingly, such a therapy was also suggested as an alternative first-line therapy in the Italian guidelines published in 2015, which was before the marketing of these tablets (2016 in Italy) and without any data from Italian trials, the first studies only now being available $[41,63]$.

The ITT eradication rate following such a quadruple therapy was $86 \%$ (95\% confidence interval [CI] 79-91\%) in 299 patients in the US [64] and $80 \%(95 \% \mathrm{CI}=74-85 \%)$ in 440 patients in 
Europe [65], whilst another international trial found an $89.3 \%$ eradication rate (modified ITT of $93 \%, 95 \% \mathrm{CI}=85.4-100 \%$ ), without any difference between patients with metronidazoleresistant or susceptible strains [66]. Unfortunately, despite the three-in-one capsule formulation, as many as 3 tablets q.i.d. for 10 days plus 2 PPI tablets are needed, that is a total of 14 tablets daily. Therefore, patients' compliance with this therapy needs to be opportunely assessed in real life, where several patients are already taking other drugs for frequent chronic diseases, such as hypertension, diabetes, cardiovascular diseases, etc. Moreover, some concerns may arise with bismuth toxicity, especially when considering the coadministration of PPIs. Although bismuth salts are scarcely absorbed $(<1 \%)$, high doses, long-term consumption and the simultaneous use of PPIs may lead to high blood levels and potential toxicity. In the past, bismuth doses of 240,300 or $480 \mathrm{mg}$ daily were generally administered for 4-10 days [67-69]. When a $480 \mathrm{mg}$ bismuth dose has been used with omeprazole for 14 days, $9 \%$ of patients have blood bismuth levels higher than $50 \mu \mathrm{g} / \mathrm{L}$, which is over the safety threshold for potential bismuth neurotoxicity, according to Hillemand's scale [70]. Note that, when the novel three-in-one capsules are used, a dose as high as $1680 \mathrm{mg}$ subcitrate potassium (corresponding to $560 \mathrm{mg}$ bismuth) is administered daily. A study found that bismuth plasma concentrations increased in $22 \%$ of patients receiving this therapy, but levels $(4-20 \mu \mathrm{g} / \mathrm{L})$ were below the toxic threshold. However, further studies on blood bismuth concentrations are needed, particularly when double-dose PPI (i.e., esomeprazole $40 \mathrm{mg}$ b.i.d.) is used [63]. For the same reason, the statement in the European guidelines suggesting that such a bismuth quadruple therapy should be extended to 14 days (unless 10-day therapies are proven effective locally) deserves at least a note of caution.

\section{Concluding remarks}

H. pylori is a strange bacterium with several peculiarities. It has been living in the human stomach for thousands of years, even though it is a pathogen. It is able to survive in the prohibitive low $\mathrm{pH}$ values of gastric juice, hidden in a peculiar ecological niche between the gastric muco-layer and the epithelium. It causes various benign and malignant diseases in the gastroduodenal tract, as well as some extra-intestinal diseases. It is a Gramnegative germ, but highly sensitive to penicillin, which acts better on the wall of Gram-positive bacteria. No single antibiotic is able to cure the infection, and even a combination of three or more compounds may be ineffective in a substantial portion of patients. No effective vaccine is available, since the bacterium can survive different approaches. Consequently, the therapeutic battle against $H$. pylori, which started in the 1980s, is still ongoing and the ideal treatment is lacking.

According to the evidence-based medicine approach, guidelines represent an undeniable advantage for the management of $H$. pylori infection in clinical practice. However, several factors are involved in the efficacy of a specific therapy regimen, including some specific host-bacteria interactions, which may be peculiar to different geographic areas. Indeed, the European guidelines clearly highlighted that the results achieved by an eradication therapy are population-specific and not directly transferable [8]. Therefore, at least the therapeutic aspects are more appropriately addressed in national than in other guidelines, providing that data from national trials are opportunely considered.

Undeniably, the role of primary resistance is relevant [71], but antimicrobial resistance in vitro does not always correlate with poor results from multi-drug treatment regimens [72]. Indeed, it should be considered that all therapy regimens include a combination of antibiotics with a potentially synergistic effect that can overcome the resistance to a single molecule. Unfortunately, the infection is not cured in all cases, even using only those antibiotics with a proven susceptibility, as demonstrated in bacterial culture-based studies [73]. A meta-analysis of 12 studies found an eradication rate of $89.2 \%(95 \% \mathrm{CI}=87.1-91.3)$ in 860 patients, despite the use of a therapy tailored according to susceptibility testing results [74]. Therefore, even if primary resistance status towards clarithromycin or levofloxacin could be assessed prior to first-line therapy, using novel stool tests based on the polymerase chain reaction technique [75], bacterial eradication is not guaranteed. Similarly, under the empirical administration of a 14-day bismuth-tetracycline-amoxicillin combination, three drugs with no or a very low $(<5 \%)$ primary resistance rate to $H$. pylori isolates, the eradication rate was as low as $43 \%$ [76].

Keeping in mind that novel antibiotics against $H$. pylori are not available, the use of those regimens with proven efficacy in a specific geographic area would appear judicious, before abandoning a therapy a priori, considering only the bacterial resistance pattern. Last but not least, the therapeutic cost of different regimens should be taken into account when considering the vast diffusion of $H$. pylori infection worldwide. In those areas where the efficacy of different therapies is similar $( \pm 5 \%)$ the cost of drugs may be a cause for concern (Table 4 ), and specific cost-effectiveness studies are needed.

\section{References}

1. Hunt RH, Xiao SD, Megraud F, et al; World Gastroenterology Organization. Helicobacter pylori in developing countries. World Gastroenterology Organisation Global Guideline. J Gastrointestin Liver Dis 2011;20:299-304.

2. Zullo A, De Francesco V, Hassan C. Predicting Helicobacter pylori eradication: How to teach an old dog new tricks! J Clin Gastroenterol 2012;46:259-261.

3. Kotilea K, Mekhael J, Salame A, et al. Eradication rate of Helicobacter pylori infection is directly influenced by adherence to therapy in children. Helicobacter 2017 Mar 17. doi: 10.1111/hel.12383 [Epub ahead of print].

4. Megraud F, Coenen S, Versporten A, et al; Study Group participants. Helicobacter pylori resistance to antibiotics in Europe and its relationship to antibiotic consumption. Gut 2013;62:34-42.

5. De Francesco V, Giorgio F, Hassan C, et al. Worldwide H. pylori antibiotic resistance: A systematic review. J Gastrointestin Liver Dis 2010;19:409-414.

6. Graham DY, Lee YC, Wu MS. Rational Helicobacter pylori therapy: Evidence-based medicine rather than medicine-based evidence. Clin Gastroenterol Hepatol 2014;12:177-186.e3.

7. Thung I, Aramin H, Vavinskaya V, et al. Review article: The global emergence of Helicobacter pylori antibiotic resistance. Aliment Pharmacol Ther 2016;43:514-533. 
8. Malfertheiner P, Megraud F, O'Morain CA, et al; European Helicobacter and Microbiota Study Group and Consensus panel. Management of Helicobacter pylori infection-the Maastricht V/Florence Consensus Report. Gut 2017;66:6-30.

9. Chey WD, Leontiadis GI, Howden CW, Moss SF. ACG Clinical Guideline: Treatment of Helicobacter pylori infection. Am J Gastroenterol 2017;112:212-239.

10. Park JY, Dunbar KB, Mitui M, et al. Helicobacter pylori clarithromycin resistance and treatment failure are common in the USA. Dig Dis Sci 2016;61:2373-2380.

11. Losurdo G, Leandro G, Principi M, et al. Sequential vs. prolonged 14-day triple therapy for Helicobacter pylori eradication: The metaanalysis may be influenced by 'geographical weighting. Int J Clin Pract 2015;69:1112-1120.

12. National Institute for Health and Care Excellence (NICE) guidelines: Gastro-eesophageal reflux disease and dyspepsia: Investigation and management (CG184). NICE 2014:1-41 [Internet]. Available from: www.nice.org.uk/guidance/cg184/ resources/gastrooesophageal-reflux-disease-and-dyspepsia-inadults-investigation-and-management-pdf-35109812699845.

13. Zagari RM, Romano M, Ojetti V, et al. Guidelines for the management of Helicobacter pylori infection in Italy: The III Working Group Consensus Report 2015. Dig Liver Dis 2015;47:903-912.

14. Gisbert JP, Molina-Infante J, Amador J, et al. IV Spanish Consensus Conference on Helicobacter pylori infection treatment. Gastroenterol Hepatol 2016;39:697-721.

15. Fallone CA, Chiba N, van Zanten SV, et al. The Toronto Consensus for the treatment of Helicobacter pylori infection in adults. Gastroenterology 2016;151:51-69.

16. Fock KM, Katelaris P, Sugano K, et al. Second Asia-Pacific Consensus Guidelines for Helicobacter pylori infection $J$ Gastroenterol Hepatol 2009;24:1587-1600.

17. Yaxley J, Chakravarty B. Helicobacter pylori eradication - an update on the latest therapies. Aust Fam Physician 2014;43:301-305.

18. Asaka M, Kato M, Takahashi S, et al; Japanese Society for Helicobacter Research. Guidelines for the management of Helicobacter pylori infection in Japan: 2009 revised edition. Helicobacter 2010;15:1-20.

19. Liu WZ, Xie Y, Cheng H, et al; Chinese Society of Gastroenterology, Chinese Study Group on Helicobacter pylori. Fourth Chinese National Consensus Report on the management of Helicobacter pylori infection. J Dig Dis 2013;14:211-221.

20. Mégraud F. Current recommendations for Helicobacter pylori therapies in a world of evolving resistance. Gut Microbes 2013;4:541-548.

21. Graham DY, Fischbach L. Helicobacter pylori treatment in the era of increasing antibiotic resistance. Gut 2010;59:1143-1153.

22. Yuan Y, Ford AC, Khan KJ, et al. Optimum duration of regimens for Helicobacter pylori eradication. Cochrane Database Syst Rev 2013;(12):CD008337.

23. Li BZ, Threapleton DE, Wang JY, et al. Comparative effectiveness and tolerance of treatments for Helicobacter pylori: Systematic review and network meta-analysis. BMJ 2015;351:h4052.

24. Paoluzi P, Iacopini F, Crispino P, et al. 2-week triple therapy for Helicobacter pylori infection is better than 1-week in clinical practice: A large prospective single-center randomized study. Helicobacter 2006;11:562-568.

25. Zagari RM, Bianchi-Porro G, Fiocca R, Gasbarrini G, Roda E, Bazzoli F. Comparison of 1 and 2 weeks of omeprazole, amoxicillin and clarithromycin treatment for Helicobacter pylori eradication: The HYPER Study. Gut 2007;56:475-479.

26. De Francesco V, Ridola L, Hassan C, et al. Two-week triple therapy with either standard or high-dose esomeprazole for first-line H. pylori eradication. J Gastrointestin Liver Dis 2016;25:147-150.

27. Molina-Infante J, Lucendo AJ, Angueira T, et al; European Registry on $H$. pylori management (Hp-EuReg). Optimised empiric triple and concomitant therapy for Helicobacter pylori eradication in clinical practice: The OPTRICON study. Aliment Pharmacol Ther 2015;41:581-589.

28. Greenberg ER, Anderson GL, Morgan DR, et al. 14-day triple, 5-day concomitant, and 10-day sequential therapies for Helicobacter pylori infection in seven Latin American sites: A randomised trial. Lancet 2011;378:507-514.

29. De Francesco V, Ierardi E, Hassan C, Zullo A. Helicobacter pylori therapy: Present and future. World J Gastrointest Pharmacol Ther 2012;3:68-73.

30. Graham DY, Shiotani A. Which therapy for Helicobacter pylori infection? Gastroenterology 2012;143:10-12.

31. De Francesco V, Hassan C, Ridola L, Giorgio F, Ierardi E, Zullo A. Sequential, concomitant and hybrid first-line therapies for Helicobacter pylori eradication: A prospective randomized study. J Med Microbiol 2014;63:748-752.

32. Gatta L, Vakil N, Vaira D, Scarpignato C. Global eradication rates for Helicobacter pylori infection: Systematic review and metaanalysis of sequential therapy. BMJ 2013;347:f4587.

33. He L, Deng T, Luo H. Meta-analysis of sequential, concomitant and hybrid therapy for Helicobacter pylori eradication. Intern Med 2015;54:703-710.

34. Kim JS, Park SM, Kim BW. Sequential or concomitant therapy for eradication of Helicobacter pylori infection: A systematic review and meta-analysis. J Gastroenterol Hepatol 2015;30:1338-1345.

35. Zullo A, De Francesco V, Hassan C, Morini S, Vaira D. The sequential therapy regimen for Helicobacter pylori eradication: A pooled-data analysis. Gut 2007;56:1353-1357.

36. Vaira D, Zullo A, Hassan C, Fiorini G, Vakil N. Sequential therapy for Helicobacter pylori eradication: The time is now! Therap $A d v$ Gastroenterol 2009;2:317-322.

37. Romano M, Cuomo A, Gravina AG, et al. Empirical levofloxacincontaining versus clarithromycin-containing sequential therapy for Helicobacter pylori eradication: A randomised trial. Gut 2010;59:1465-1470.

38. Zullo A, Scaccianoce G, De Francesco V, et al. Concomitant, sequential, and hybrid therapy for $H$. pylori eradication: A pilot study. Clin Res Hepatol Gastroenterol 2013;37:647-650.

39. Manfredi M, Bizzarri B, de'Angelis GL. Helicobacter pylori infection: Sequential therapy followed by levofloxacin-containing triple therapy provides a good cumulative eradication rate. Helicobacter 2012;17:246-253.

40. Manfredi M, Bizzarri B, Sacchero RI, et al. Helicobacter pylori infection in clinical practice: Probiotics and a combination of probiotics + lactoferrin improve compliance, but not eradication, in sequential therapy. Helicobacter 2012;17:254-263.

41. Di Ciaula A, Scaccianoce G, Venerito M, et al. Eradication rates in Italian subjects heterogeneously managed for $\mathrm{H}$. pylori infection. Time to abandon empiric treatments in Southern Europe. $J$ Gastrointestin Liver Dis 2017. [In press].

42. Franceschi F, Ojetti V, Gabrielli M, et al. High dose amoxicillin-based first line regimen is equivalent to sequential therapy in the eradication of H. pylori infection. Eur Rev Med Pharmacol Sci 2016;20:297-300.

43. Tepeš B, Vujasinović M, Šeruga M, Stefanovič M, Forte A, Jeverica S. Randomized clinical trial comparing 10-day sequential, 7-day concomitant and 7-day standard triple therapies for Helicobacter pylori eradication. Eur J Gastroenterol Hepatol 2016;28:676-683.

44. Branquinho D, Almeida N, Gregório C, et al. Levofloxacin or Clarithromycin-based quadruple regimens: What is the best alternative as first-line treatment for Helicobacter pylori eradication in a country with high resistance rates for both antibiotics? BMC Gastroenterol 2017;17:31.

45. Schmilovitz-Weiss H, Schmiloviz-Weiss H, Shalev T, et al. High eradication rates of Helicobacter pylori infection following sequential therapy: The Israeli experience treating naïve patients. Helicobacter 2011;16:229-233. 
46. Phiphatpatthamaamphan K, Vilaichone RK, Siramolpiwat S, et al. Effect of IL-1 polymorphisms, CYP2C19 genotype and antibiotic resistance on Helicobacter pylori eradication comparing between 10-day sequential therapy and 14-day standard triple therapy with four-times-daily-dosing of amoxicillin in Thailand: A prospective randomized study. Asian Pac J Cancer Prev 2016;17:1903-1907.

47. Liou JM, Chen CC, Chang CY, et al; Taiwan Gastrointestinal Disease and Helicobacter Consortium. Sequential therapy for 10 days versus triple therapy for 14 days in the eradication of Helicobacter pylori in the community and hospital populations: A randomised trial. Gut 2016;65:1784-1792.

48. Ang TL, Fock KM, Song M, et al. Ten-day triple therapy versus sequential therapy versus concomitant therapy as first-line treatment for Helicobacter pylori infection. J Gastroenterol Hepatol 2015;30:1134-1139.

49. Abuhammour A, Dajani A, Nounou M, Zakaria M. Standard triple therapy versus sequential therapy for eradication of Helicobacter pylori in treatment naïe and retreat patients. Arab J Gastroenterol 2016;17:131-136.

50. Georgopoulos SD, Xirouchakis E, Martinez-Gonzales B, et al. Randomized clinical trial comparing ten day concomitant and sequential therapies for Helicobacter pylori eradication in a high clarithromycin resistance area. Eur J Intern Med 2016;32:84-90.

51. McNicholl AG, Marin AC, Molina-Infante J, et al; Participant Centres. Randomised clinical trial comparing sequential and concomitant therapies for Helicobacter pylori eradication in routine clinical practice. Gut 2014;63:244-249.

52. Haider RB, Brennan DE, Omorogbe J, et al. A randomizedcontrolled study to compare the efficacy of sequential therapy with standard triple therapy for Helicobacter pylori eradication in an Irish population. Eur J Gastroenterol Hepatol 2015;27:1265-1269.

53. Rakici H, Akdoğan RA, Bedir R, Copur A, Yilmaz A. Comparison of standard triple therapy, sequential therapy and moxifloxacinbased triple therapy for Helicobacter pylori infection: Patients' compliance and bacterial eradication rates. J Dig Dis 2014;15:508513.

54. Sardarian H, Fakheri H, Hosseini V, Taghvaei T, Maleki I, Mokhtare M. Comparison of hybrid and sequential therapies for Helicobacter pylori eradication in Iran: A prospective randomized trial. Helicobacter 2013;18:129-134.

55. Lee JW, Kim N, Kim JM, et al. A comparison between 15-day sequential, 10-day sequential and proton pump inhibitor-based triple therapy for Helicobacter pylori infection in Korea. Scand J Gastroenterol 2014;49:917-924.

56. Zhou L, Zhang J, Chen M, et al. A comparative study of sequential therapy and standard triple therapy for Helicobacter pylori infection: A randomized multicenter trial. Am J Gastroenterol 2014; 109:535-541.

57. Warrington E, López-Román O, Tirado Montijo R, Urbina R, Cruz-Correa M, Toro DH. Neither 10- nor 14-day sequential treatment is better than standard triple therapy for Helicobacter pylori eradication. P R Health Sci J 2016;35:203-208.

58. Morse AL, Goodman KJ, Munday R, et al; CANHelp Working Group. A randomized controlled trial comparing sequential with triple therapy for Helicobacter pylori in an Aboriginal community in the Canadian North. Can J Gastroenterol 2013;27:701-706.

59. Lefebvre M, Chang HJ, Morse A, van Zanten SV, Goodman KJ; CANHelp Working Group. Adherence and barriers to H. pylori treatment in Arctic Canada. Int J Circumpolar Health 2013;72:22791.

60. de Boer WA, Driessen WM, Potters VP, Tytgat GN. Randomized study comparing 1 with 2 weeks of quadruple therapy for eradicating Helicobacter pylori. Am J Gastroenterol 1994;89:1993-1997.

61. de Boer WA, van Etten RJ, Schade RW, Ouwehand ME, Schneeberger PM, Tytgat GN. 4-day lansoprazole quadruple therapy: A highly effective cure for Helicobacter pylori infection. Am J Gastroenterol 1996;91:1778-1782.

62. de Boer WA. A novel therapeutic approach for Helicobacter pylori infection: The bismuth-based triple therapy monocapsule. Expert Opin Investig Drugs 2001;10:1559-1566.

63. Tursi A, Di Mario F, Franceschi M, et al. New bismuth-containing quadruple therapy in patients infected with Helicobacter pylori: A first Italian experience in clinical practice. Helicobacter 2017;22. doi: 10.1111/hel.12371.

64. Laine L, Hunt R, El-Zimaity H, Nguyen B, Osato M, Spénard J. Bismuth-based quadruple therapy using a single capsule of bismuth biskalcitrate, metronidazole, and tetracycline given with omeprazole versus omeprazole, amoxicillin, and clarithromycin for eradication of Helicobacter pylori in duodenal ulcer patients: A prospective, randomized, multicenter, North American trial. Am J Gastroenterol 2003;98:562-567.

65. Malfertheiner P, Bazzoli F, Delchier JC, et al; Pylera Study Group. Helicobacter pylori eradication with a capsule containing bismuth subcitrate potassium, metronidazole, and tetracycline given with omeprazole versus clarithromycin-based triple therapy: A randomised, open-label, non-inferiority, phase 3 trial. Lancet 2011;377:905-913.

66. O’Morain C, Borody T, Farley A, et al; International multicentre study. Efficacy and safety of single-triple capsules of bismuth biskalcitrate, metronidazole and tetracycline, given with omeprazole, for the eradication of Helicobacter pylori: An international multicentre study. Aliment Pharmacol Ther 2003; 17:415-420.

67. Lerang F, Moum B, Ragnhildstveit E, et al. A comparison between omeprazole-based triple therapy and bismuth-based triple therapy for the treatment of Helicobacter pylori infection: A prospective randomized 1-yr follow-up study. Am J Gastroenterol 1997;92:653-658.

68. de Boer SY, van der Meeberg PC, de Boer WA. Comparison of four-day and seven-day pantoprazole-based quadruple therapy as a routine treatment for Helicobacter pylori infection. Netherland $J$ Med 2003;61:218-222.

69. Fallone CA, Loo V, Joseph L, Barkun J, Kostyk R, Barkun A. predictors of failure of Helicobacter pylori eradication and predictors of ulcer recurrence: A randomized controlled trial. Clin Invest Med 1999;22:185-194.

70. Phillips RH, Whitehead MW, Doig LA, et al. Is eradication of Helicobacter pylori with colloidal bismuth subcitrate quadruple therapy safe? Helicobacter 2001;6:151-156.

71. McNulty CA, Lasseter G, Shaw I, et al. Is Helicobacter pylori antibiotic resistance surveillance needed and how can it be delivered? Aliment Pharmacol Ther 2012;35:1221-1230.

72. Graham DY, de Boer WA, Tytgat GN. Choosing the best antiHelicobacter pylori therapy: effect of antimicrobial resistance. Am J Gastroenterol 1996;91:1072-1076.

73. Romano M, Marmo R, Cuomo A, et al. Pretreatment antimicrobial susceptibility testing is cost saving in the eradication of Helicobacter pylori. Clin Gastroenterol Hepatol 2003;1:273-278.

74. López-Góngora S, Puig I, Calvet X, et al. Systematic review and meta-analysis: Susceptibility-guided versus empirical antibiotic treatment for Helicobacter pylori infection. J Antimicrob Chemother 2015;70:2447-2455.

75. Ierardi E, Giorgio F, Iannone A, et al. Noninvasive molecular analysis of Helicobacter pylori: Is it time for tailored first-line therapy? World J Gastroenterol 2017;23:2453-2458.

76. Graham DY, Lew GM, Ramirez FC, Genta RM, Klein PD, Malaty HM. Short report: A non-metronidazole triple therapy for eradication of Helicobacter pylori infection-tetracycline, amoxicillin, bismuth. Aliment Pharmacol Ther 1993;7:111-113. 